\title{
Relações de Substância e Consumo de Álcool entre os Mbyá-Guarani ${ }^{1}$
}

\author{
Luciane Ouriques Ferreira
}

Universidade Federal de Santa Catarina, Florianópolis, Brasil

E-mail: lu.ouriquesf@gmail.com 


\section{Resumo}

Os Mbyá-Guarani costumam afirmar que a bebida alcoólica possui um espírito que não tem parente e, por isso, ao consumi-la, a pessoa pode comprometer o vínculo social com os seus familiares. A partir dessa premissa propõe-se refletir sobre como o idioma da substancialidade que informa as relações de parentesco sustenta a compreensão nativa sobre os efeitos gerados pelas bebidas alcoólicas introduzidas pelo contato, no âmbito das aldeias no Rio Grande do Sul. Para tanto, considera-se os dados etnográficos que emergiram no contexto da pesquisa-ação sobre o consumo de álcool realizada junto aos Mbyá, entre os anos 2000 e 2004. Esses dados demonstram quanto a lógica da substancialidade ordena as relações não só entre parentes Mbyá, mas também entre eles e os seres e "coisas" advindas do mundo dos brancos.

Palavras-chave: Relações de Substância. Bebidas Alcoólicas. Mbyá-Guarani.

\section{Abstract}

The Mbyá-Guarani usually affirm that the alcoholic drinks has a spirit that has no relative and therefore when consuming it the person can compromise the social bond with its relatives. Based on this premise, I propose to reflect on how the language of substantiality that informs kinship relations supports the native understanding of the effects of alcoholic drinks introduced by contact within the villages in Rio Grande do Sul. Ethnographic studies that emerged in the context of the action research on alcohol consumption carried out among the Mbya between the years 2000 and 2004. These data demonstrate how much the logic of substantiality orders relations not only between Mbyá relatives, but also between them and the beings and 'things' from the white world.

Keywords:Substance Relations. Alcoholic Drinks. Mbyá-Guarani. 


\section{Introdução}

Os Mbyá-Guarani no Estado do Rio Grande do Sul costumam afirmar que a bebida alcoólica, chamada por eles de canha, possui um espírito que não tem parente e, por isso, a pessoa ao consumila poderá vir a comprometer o vínculo com os seus parentes mais próximos, gerando uma série de efeitos disruptivos no âmbito de suas comunidades. A partir dessa premissa proponho analisar o consumo de álcool entre os Mbyá a partir das teorias que consideram o corpo humano como uma construção sociocultural, lugar onde se inscreve os valores e significados da sociedade que o modela. Por corpo estou compreendendo um conjunto de afetos, afecções, capacidades ou modos de ser constitutivos de um habitus, que se expressa no "[...] que ele come, como se move, como se comunica, onde vive, se é gregário ou solitário" (Viveiros de Castro, 1996, p. 128).

A produção de corpos e de pessoas realizada por meio da partilha de substâncias é central para a compreensão de como são criados, mantidos e atualizados os vínculos sociais e os sistemas de parentesco entre os povos indígenas. Entre os Mbyá, as teorias de corporalidade, ao fazer a mediação simbólica entre parentes, instituem o parentesco como relações de substância. A partilha de fluídos corporais nos espaços da intimidade familiar e o compartilhar de alimentos e bebidas em diferentes momentos da socialidade cotidiana propiciam a produção de pessoas aparentadas e a atualização dos vínculos de parentesco. A lógica da substancialidade, no entanto, não se restringe ao socius Mbyá-Guarani, mas tende a ordenar as relações estabelecidas com os outros que habitam o cosmos. Dentre esses outros estão os juruá (não- 
Mbyá) e as coisas provenientes de seu mundo, sendo um desses ser-coisa a própria bebida alcoólica, chamada por eles de canha (Ferreira, 2002).

Sendo assim, meu objetivo é refletir sobre como o idioma de substancialidade informa a compreensão Mbyá dos efeitos gerados pelas bebidas alcoólicas introduzidas pelo contato interétnico no âmbito das suas aldeias ${ }^{1}$. Para tanto, considerarei os dados etnográficos que emergiram no contexto da pesquisa-ação sobre o consumo de álcool realizada junto aos Mbyá-Guarani do RS entre os anos 2000 e 2004. Esses dados emergiram durante distintas situações de pesquisa: 1) no diagnóstico antropológico participativo sobre o alcoolismo (Ferreira, 2002; Ferreira, 2004b); 2) nas reuniões dos karaí (sábios e líderes espirituais) (Ferreira, 2009); e 3 ) nos encontros realizados pelos xondaro marãgatu (guardiões das boas palavras) (Ferreira, 2004). Esses eventos comunicativos propiciaram que o aconselhamento por meio das boas palavras (ayvu porã ), gênero de fala cerimonial que compõe a arte verbal Mbyá, emergissem como prática de autoatenção utilizada para intervir sobre os agravos e problemas sociais gerados pelo uso abusivo de bebidas alcoólicas no contexto de suas comunidades. São esses discursos que nos oferecerão o material etnográfico sobre o qual se sustenta a análise acerca da importância que o idioma de substancialidade assume na mediação simbólica das relações sociais estabelecidas entre os parentes Mbyá, ao mesmo tempo em que informa a compreensão das lideranças espirituais sobre o uso de bebidas alcoólicas e, em decorrência, sobre as próprias relações estabelecidas com os seres e as coisas do mundo do juruá ${ }^{2}$.

\section{Corporalidade e Partilha de Substâncias}

Com a constatação de que os modelos antropológicos formais empregados para análise dos sistemas de parentesco africanos seriam inadequados para compreender o parentesco nas sociedades indígenas da América do Sul (Da Matta, 1979), a ênfase da análise etnológica é deslocada para o conteúdo que informa as relações entre parentes. Desde então, o corpo passa a ser considerado categoria central para a compreensão das relações de parentesco ameríndias. Uma linguagem sustentada sobre uma fisiologia dos fluidos corporais 
- sangue, sêmen, leite - e dos processos de comunicação do corpo com o mundo (alimentação, sexualidade, fala e demais sentidos) ordenaria a vida social das sociedades indígenas sul-americanas, sendo o corpo o lugar onde se articulam as diferentes instâncias constitutivas da pessoa.

A teoria da corporalidade desenvolvida por Seeger, Da Matta e Viveiros de Castro (1987) defende que a fabricação e a modelagem do corpo empreendida pelas sociedades indígenas têm como objetivo a formação e a construção da pessoa e das identidades sociais (Viveiros de Castro, 1987). Essas teorias constituiriam um idioma simbólico focal que atuam como princípios centrais da organização social e dos sistemas de parentesco, operacionalizando e informando a práxis. Por meio das relações corporais a interação entre as pessoas seria instrumentalizada.

No contexto dos sistemas de parentesco, o processo de produção dos corpos tem como resultado a construção da 'pessoa aparentada'. As teorias nativas de concepção, reprodução e ciclos vitais demonstram como são formados os laços de identidade corporal que orientam as relações de substância instituindo-as como base dos grupos de parentesco. Nos "[...] grupos de pessoas relacionadas por 'substância' [...] um indivíduo é literalmente criado como membro de um grupo na sua própria carne, sangue e ossos" (Seeger, 1980, p. 130).

Nos mundos indígenas, as identificações substanciais são consequência de relações sociais e não o contrário: as relações de parentesco não exprimem 'culturalmente' uma conexão corporal 'naturalmente' dada; os corpos são criados pelas relações, não as relações pelos corpos'. (Viveiros de Castro, 2002, p. 447)

Os estudos realizados entre os Apinayé (Da Matta, 1979) e entre os Piro e Campa (Gow, 1991) ilustram como a lógica da substancialidade estrutura as relações sociais entre pessoas aparentadas. Para Da Matta (1979), o sistema de parentesco Apinayé constitui um sistema de relações sociais, ideologicamente organizado pelo idioma de substancialidade. A família nuclear, que opera com o princípio da uxoralidade como regra de residência, seria reconhecida como uma unidade produtora de crianças, sendo a casa o lugar onde acontece a vida doméstica Apinayé. Duas ideologias são encontradas neste âmbito: as regras de 
evitação e de etiqueta que regulam, por exemplo, as relações entre afins que habitam a mesma residência - entre genro e sogro e entre cunhados; e as precauções, abstinências ou restrições relacionadas tanto a alimentação quanto a comportamentos que se deve adotar nos períodos de couvade/resguardo. Estas ideologias estão fundadas sobre as concepções nativas a respeito do correto funcionamento do corpo, que depende da combinação adequada de substâncias tanto durante a gravidez e no período pós-parto, quanto na menstruação e em casos de doença (Da Matta, 1979).

A teoria que informa as práticas realizadas durante a couvade aponta para uma continuidade entre pessoas que pertencem a uma mesma família nuclear, transformando-a em uma comunidade de substância. Essa comunidade de substância, a quem cabe a responsabilidade de promover e zelar pelo bem-estar de seus membros, agrega tanto consanguíneos quanto afins, na medida em que marido e mulher compartilham fluidos corporais e alimentos. Enquanto o idioma de substancialidade informaria as relações Apinayé no âmbito doméstico, as relações entre os grupos cerimoniais seriam instituídas por meio de rituais de passagem que separariam a pessoa de sua comunidade de substância original, preparando-a para formar a sua própria família.

Já Gow (1991), ao estudar a sociedade Piro e Campa do Baixo Urubamba vai reconhecer dois idiomas organizadores das relações sociais de parentesco: o idioma da substancialidade, baseado na conexão física e substâncias compartilhadas, e o idioma do cuidado. O idioma da substancialidade é revelado por meio das proibições pós-parto, a serem cumpridas pelos pais do recém-nascido, momento onde o corpo da criança tem uma ligação de contiguidade com o corpo dos pais, pois sua alma, apesar de ser independente, é ignorante e pode ser perdida diante de determinadas situações. O idioma do cuidado, por sua vez, se estabelece a partir do momento em que a criança desmama e começa a andar. A partir daí os pais devem alimentá-la com a comida verdadeira criando uma memória recíproca de amor que se estenderá por toda a vida adulta da pessoa.

Os idiomas que informam o processo de produção da pessoa aparentada também influenciam a construção da identidade de 
gênero da sociedade do Baixo Urubamba. É o sistema de trocas e de obrigações recíprocas entre marido e mulher, no âmbito da economia de subsistência, que coloca em movimento a produção dos chamados alimentos verdadeiros. Se por um lado, os cônjuges devem satisfazer os desejos sexuais um do outro, por outro eles devem atender as suas exigências alimentares: o homem deve trazer carne de caça para a sua mulher e a mulher deve fazer cerveja de mandioca para o homem. É essa dinâmica que permite a manutenção dos idiomas centrais do parentesco que informam as relações entre os familiares e a produção de pessoas aparentadas e engendradas.

Gow (1991) ainda reconhece mais um terceiro idioma organizador das relações de parentesco: o da corresidência. Esse idioma se desenvolveria a partir do cuidado dedicado pelos pais aos seus filhos, abarcando as demais relações estabelecidas entre aqueles que vivem juntos em uma mesma comunidade, entre aqueles que convivem e que trocam alimentos. Se a comunidade é um fenômeno do parentesco; o parentesco é um efeito da comunidade, pois viver juntos é a demonstração e a atualização dos laços de parentesco. Diferente dos Apinayé (Da Matta, 1979) o idioma de substância e o do cuidado não se restringem ao âmbito doméstico, mas também estruturam a relação entre parentes co-residentes que trocam alimentos entre si (Gow, 1991).

\section{Organização Social e Parentesco Guarani}

Existe uma lacuna nos estudos etnológicos clássicos sobre o parentesco Guarani (Viveiros de Castro, 1986; Saez, 2004; Pissolato, 2007), particularmente, sobre as relações entre parentes Mbyá. Encontramos informações etnográficos sobre os Guarani nas investigações realizadas por Schaden (1954), Littaif (1996) e Pereira (1999). Soares (1997) apresenta algumas informações historiográficas sobre a organização social Guarani. Os estudos etnológicos sobre os Guarani (Schaden 1954; Bartolomé 1991), no geral, compreendem o parentesco como princípio de estruturação da vida social situando a família extensa como unidade social básica de produção econômicareligiosa e política (Pissolato, 2007). 
Schaden (1954) afirma que a organização social Guarani está baseada na família extensa. Este mesmo grupo é definido por Soares (1997) como kindred, ou seja, um grupo de parentes ligados por laços de consanguinidade e de afinidade organizados em torno a uma pessoa de prestígio que pode ser a liderança política e/ou religiosa do grupo. O cunhadasco (tovajá) constituiria instituição central da organização social Guarani, pois por meio dele seriam estabelecidas as alianças entre afins. Nesse sentido, a forma poligâmica dos casamentos, comum na história Guarani, constituiria uma maneira de ampliar o rol dos aliados políticos, tornando o outro em cunhado (Soares, 1997).

No RS, a maior parte das aldeias é composta de uma família extensa principal e outras famílias agregadas a esta por afinidade ou por aliança de natureza política. Cada família nuclear que reside em uma aldeia possui sua própria casa e o seu fogo de chão usado para cozinhar, esquentar a água para o chimarrão, aquecer, preparar remédios e esquentar os ferros com os quais são preparadas as esculturas em madeira. Em um local estratégico das aldeias encontraremos a casa de reza (opy), local onde reside o karai opygua (liderança espiritual) e sua esposa e onde são realizadas as cerimônias sagradas (Ferreira, 2001).

Segundo Littaif (1996) a regra de residência Guarani-Mbyá é uxorilocal e temporária, ou seja, o homem habita com a família da esposa, prestando serviço para os sogros até o nascimento do primeiro filho, depois o casal estaria livre para escolher o lugar para morar. Soares (1997) contesta esta informação defendendo a ideia de que a regra de residência é definida pelo prestígio da liderança do grupo. A pesquisa que realizei entre os Mbyá no RS demonstra que a regra vigente é a da uxorilocalidade temporária, entretanto, os chefes de prestígio podem influir sobre a situação e fazer com que suas noras venham morar junto a seus filhos, por exemplo (Ferreira, 2001).

Diante da ausência de uma regra matrimonial positiva-prescritiva, o fator que, tradicionalmente, orientava a escolha do cônjuge por parte da família do jovem que pretendia se casar, seria a busca por prestígio político (Soares, 1997). No RS os Mbyá falam que antigamente as famílias é que decidiam sobre o casamento dos filhos, mas que atualmente o cônjuge é escolhido diretamente pelos jovens. Isso não 
isenta ao homem de consultar os pais da noiva e pedir a permissão para o casamento. O casamento é ministrado pelo cacique, que aconselha os recém-casados quanto aos deveres e direitos dos cônjuges. É o cacique que também intervirá em caso de problemas e discórdias entre o casal.

Ao tentar desenvolver uma abordagem alternativa à forma clássica de entendimento sobre o parentesco Guarani, definido como grupo de parentes - a família extensa - que, reunidos sob determinada liderança político-religiosa, atuaria como unidade de troca no âmbito de sistema de reciprocidade, Pissolato (2007) realiza uma etnografia sobre os significados fundamentais do parentesco entre os Mbyá na contemporaneidade. Para ela, o parentesco, como processo voltado para a produção de pessoas, emerge a partir das relações interpessoais e da busca de satisfação e alegria associada a prática dos deslocamentos entre aldeias ${ }^{3}$.

A palavra usada entre os Mbyá para designar parente é -etarã, termo que pode ser usado de modo mais ou menos inclusivo, designando tanto a relação entre a pessoa e seus consanguíneos, quanto os membros desse grupo étnico. Segundo a autora, dois momentos são decisivos para a produção do parentesco Mbyá: os casamentos, realizados a partir das disposições pessoais dos indivíduos; e os deslocamentos entre aldeias que instituem a multilocalidade espaciotemporal como característica da forma social ( $\underline{\text { socius }}$ ) desse povo na atualidade (Pissolato, 2007, p. 176).

O casamento constitui uma das fortes motivações pessoais para o deslocamento de sujeitos e coletivos Mbyá e desempenha papel fundamental na constituição do universo multilocal de parentesco. "Casar é criar relação onde ela não existia (entre não parentes) e, por meio dela, produzir novas relações de parentesco com a concepção de crianças" (Pissolato, 2007, p. 207). Já a forma multilocal, ao criar condições para a busca de parentes e para a experimentação de relações em um universo social múltiplo, propicia uma abertura para a atualização das relações de parentesco.

O ideal de sociabilidade Mbyá é a vida entre parentes que produz cotidianamente as relações. "Não basta ter parentes, viver com eles é o que se deseja, criar satisfação nesta convivência. [...] É possível viver o parentesco onde for possível experimentar a 'alegria' e 'saúde' que 
este modus vivendi for capaz de produzir" (Pissolato, 2007, p. 189; 195). Se os parentes são muitos e residem em diferentes aldeias, a possibilidade de o sujeito vivenciar o parentesco em múltiplos contextos está sempre presente.

Portanto, a consciência do parentesco entre os Mbyá articularia uma perspectiva local, lugar do convívio orientado pelos ideais de partilha, proteção e troca pacífica; e a dimensão multilocal que instituiria o contexto de diversas possibilidades de experimentação do parentesco. Nesse sentido, o parentesco constituiria uma estrutura em aberto que se realiza na movimentação das pessoas e coletivos Mbyá. Como parentesco em aberto, ele constitui " [...] antes de tudo uma possibilidade (de relação) num espaço e tempo não determinados; implica uma abertura para o que virá-a-ser" (Pissolato, 2007, p. 213).

No entanto, o trabalho do parentesco também está voltado para proteger e fortalecer as pessoas por ele vinculadas, por meio da aquisição das capacidades e saberes que promovem saúde e alegria e são provenientes da própria relação estabelecida com as divindades criadoras dos espíritos das pessoas Mbyá: os nhe’ë. Dessa forma, “[...] a produção de pessoas Mbyá e a reprodução social dependem da reposição continuada de capacidades que vêm de fora do socius, aqui especificamente do domínio divino" (Pissolato, 2007, p. 415). Portanto, antes de considerarmos o parentesco Mbyá em termos de relações de substâncias será necessário nos determos sobre a dimensão cosmológica que informa os significados atribuídos ao parentesco e aos regimes de socialidade indígena.

\section{Dualidade da Alma e a Pessoa Guarani}

Se os estudos etnológicos clássicos apresentam informações dispersas acerca da organização social e do sistema de parentesco Guarani, todos eles são unânimes em afirmar a preponderância do sistema religioso sobre as demais dimensões culturais dessas sociedades indígenas (Nimuendajú, 1987; Clastres, 1978; Cadógan, 1950; Meliá, 1988; 1989; Schaden, 1954). Apesar de essa perspectiva analítica já ter sido superada por pesquisas recentes realizadas junto aos Guarani 
(Saez, 1984; Ferreira, 2001; Pissolato, 2007; Testa, 2014), dois temas foram amplamente explorados por estes autores e influenciaram fortemente a produção etnológica sobre essas sociedades: um deles foi a dualidade da alma como chave para a compreensão do seu sistema religioso e a sua associação com a centralidade que linguagem possui entre os Guarani; e o outro foi o das grandes migrações em busca da terra sem mal.

Apesar de Pissolato (2007) defender que a dualidade da alma não está posta para os Mbyá, minha experiência etnográfica demonstra que para eles existe um espírito de origem divina (nhe'ë) e outro de procedência telúrica ( $\underline{\text { an }})$. Os nhe'ë são provenientes das moradas dos quatro pais verdadeiros dos espíritos: Nhamandu, Karaí, Tupã, Jakairá.

Quando Nhamandu Ru Ete concebeu as demais divindades - Caraí Ru Ete (leste), Jacaíra Ru Ete (zênite) e Tupã Ru Ete (oeste) - conferiu-lhes o encargo das almas-palavras dos futuros homens; são estas divindades, por essa razão, chamadas de Ñe'eng Ru Ete (pais verdadeiros das almaspalavras) que o xamã (no ritual de batismo) invoca para saber de onde vem a alma da criança e qual é o seu nome. (Clastres, 1978, p. 88)

Schaden (1954, p. 138) define o nhe'ë como um tipo de espírito protetor que zela pela segurança do sujeito e que, ao mesmo tempo, possui uma "[...] existência relativamente livre, isto é, existem independentemente do corpo, podendo deixá-lo [...] e retirar-se para regiões longínquas". Segundo um jovem Mbyá o nhe’ë é o princípio da pessoa, é o espírito que sustenta a sua vida e determina a sua forma de ser. "Nós, seres humanos, somos apenas representações imperfeitas deste ser perfeito que é o espírito-nome nhe “ë" (Poty, 2015, p. 29).

Devido a sua capacidade de comunicar-se com as divindades (nhanderu: nosso pai) ao karaí (xamã) é revelado o nome do nhe'ë das crianças durante o ritual do batismo (nhemongaraí), que ocorre por ocasião do ciclo do ano novo (ara pyau), entre os meses de janeiro e fevereiro. Nesse momento, Nhanderu informa sobre a procedência do espírito e a filiação divina do espírito da pessoa. "O nome a seus olhos, é a bem dizer um pedaço de seu portador, ou mesmo quase idêntico a ele, inseparável da pessoa. O Guarani não 'se chama' fulano de tal, 
mas ele 'é' este nome" (Nimuendajú, 1987, p. 32). De sua conexão com o nome divino dependerá a saúde e o bem-viver da pessoa, pois é ele que "sustentará erguido o fluir do seu dizer" (Cadógan, 1950).

Já o espírito telúrico chamado an, também traduzido pelos Mbyá como princípio vital que anima o vivente, constitui o princípio terrestre que a pessoa adquire junto ao corpo quando o nhe'ë encarna na terra. Ele se desenvolve no decorrer da vida da pessoa como efeito do seu modo imperfeito de viver (tekoaxy) e se transforma em espírito do morto

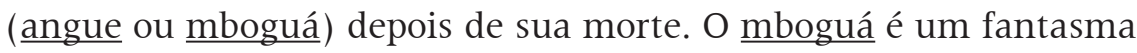
muito temido, que vaga pelos lugares onde a pessoa transitou em vida e pode causar doenças ao se aproximar dos seus parentes (Ferreira, 2002; Ferreira, 2004).

Se a morte fragmenta a pessoa fazendo com que "corpo, alma e sombra explodam em direções diversas e divergentes" (Viveiros de Castro, 1986, p. 495) - o nhe'ë retorna para a sua morada divina, o corpo apodrece e o an se transforma em mboguá -; a vida requer que a pessoa Mbyá busque o equilíbrio entre as tendências dos dois espíritos que a constitui. São as qualidades imperfeitas do tekoaxy que a pessoa deve superar por meio do resguardo sexual, de restrições alimentares e de comportamentos adequados, para manter a sua saúde, se proteger das agressões dos seres que habitam o cosmos e viver bem e com alegria junto aos seus parentes. Dessa forma, ela vive buscando se equilibrar entre os ensinamentos repassados pelos deuses e que traz em seu nhe'ë e os apelos do mundo tekoaxy que busca capturá-la por meio de inúmeras situações que mobilizam a sua subjetividade. Aqui se manifesta o ideal de pessoa Mbyá-Guarani como devir-outro, como "um entre" (Viveiros de Castro, 1986), já que a alteridade a constitui e a mantém na linha tênue e tensa entre as duas almas.

\section{O Idioma da Substancialidade entre os Mbyá-Guarani}

Pissolato acredita que entre os Mbyá o parentesco é definido nos termos da consanguinidade, sendo o vínculo de filiação determinante na definição dos parentes de uma pessoa. Nesse caso, os Mbyá não considerariam o esposo ou esposa como parentes, já que o fenômeno de consubstancialização não ocorreria. “A experiência de convivência 
entre afins não apaga a distinção conceitual que os classifica, em princípio, como não-parentes" (Pissolato, 2007, p. 182). Por outro lado, a autora defende que o parentesco decorre de atos sociais, onde o processo de aparentamento é concebido nos termos da partilha de substâncias. No entanto, a etnografia realizada por ela não apresenta informações sobre como o idioma de substancialidade informa as relações entre parentes Mbyá.

Ao contrário do que foi constatado por Pissolato, minha experiência junto ao Mbyá demonstra que os cônjuges, a partir do momento que passam a conviver e partilhar suas vidas constituem uma comunidade de substância, tal como descrita por Da Matta para os Apinayé, conectada por vínculos corporais específicos. Tanto os cuidados que os cônjuges devem adotar com a gestação, quanto a prática dos resguardos pós-parto apontam para a existência de vínculos corporais construídos a partir da partilha de substâncias: sangue, sêmen, leite e alimentos (Ferreira, 2013). A convivência e a troca de fluidos corporais transformam pessoas, a princípio não vinculadas por laços de parentesco, em família, consequentemente, em parente. Nesse sentido, defendo que a dimensão local da convivência entre parentes, mais especificamente o âmbito das relações familiares, constitui o lugar por excelência do estabelecimento das relações de substância entre os Mbyá. São essas relações fundamentais no processo de construção de corpos e de produção da pessoa aparentada.

Schaden (1954) interpreta os resguardos como estados de crise que envolvem momentos relacionados ao ciclo vital - o nascimento, maturação biológica, doenças, nascimento dos filhos e morte. Para esse autor o resguardo e as restrições alimentares a que se submete o pai durante o período pós-parto rementem a “[...] extensão, para o pai, de medidas de precaução necessárias à segurança do recém-nascido. Através de uma espécie de participação, o pai representa o filho e, até certo ponto, também a mãe" (Schaden, 1954, p. 81). Apesar de o autor não associar essas práticas à produção de parentesco entre os Guarani, é justamente nos períodos de resguardo pós-parto que as relações de substância se tornam evidentes. O período da menarca feminina, quando a mulher não deve cozinhar e nem manter relações sexuais, também remete ao idioma da substancialidade. 
Pissolato (2007), ao definir o parentesco pela sua função de proteção, também apresenta dados etnográficos que vem a corroborar a ideia de que o parentesco Mbyá, principalmente no que diz respeito a sua dimensão local e de convívio, é informado pelo idioma da substancialidade.

Com o objetivo de aparentar uma criança pequena, seus pais resguardam-se para proteger sua saúde, buscam meios de achar-lhe o nome, enfumaçam constantemente sua cabeça com petyngua [cachimbo], ministram-lhe os remédios que sabem fazer e levam-na para que outros parentes a tratem com seus conhecimentos. (Pissolato, 2007, p. 337)

Segundo Larricq (1993), a mulher Mbyá possui uma fecundidade localizada que é instigada pela vontade divina, entretanto durante a gestação sua função é passiva, cabendo ao homem a tarefa de formar o sangue e o corpo do feto da criança por meio do intercurso sexual durante a gravidez. Em torno do sangue gira uma série de concepções e de cuidados no sentido de mantê-lo puro. Esse cuidado com a manutenção da pureza do sangue é primordial para que o nhe'ë permaneça ligado ao corpo da pessoa (Ferreira, 2013).

Quando uma criança nasce os pais devem permanecer em reclusão porque existe o perigo do nhe'ë do recém-nascido acompanhá-los em suas andanças e terminar por perder-se no caminho. Assim como entre os Piro e Campa estudados por Gow (1991), entre os Mbyá o resguardo pós-parto observado pela mãe e pelo pai durante, aproximadamente, trinta dias, revela que, enquanto o novo corpo ainda está em formação, ele possui uma ligação de contiguidade corporal com os seus genitores. Por isso, qualquer atitude inapropriada de seus pais, tanto no que se refere às dietas, quanto às condutas e relações, pode afetar a criança causando-lhe doenças. Nesse período, o nhe'ë do recém-nascido está especialmente ligado aos pais.

Por ocasião do nascimento de sua sétima filha, um cacique me explicou sobre os cuidados e procedimentos que os pais e a família devem ter no período pós-parto. Ao me falar sobre esse tema, ele tinha como intenção a elaboração de um documento para ser encaminhado ao Ministério Público Federal reivindicando o direito à atenção diferenciada 
a gestação, ao parto e ao puerpério Mbyá. Isso porque sua filha nasceu no hospital e teve que permanecer por alguns dias na Unidade de Tratamento Intensiva (UTI) Neonatal. A maior preocupação dele e de sua esposa nesse momento era de que os profissionais de saúde não

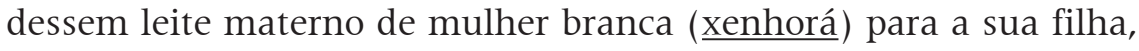
pois se isso acontecesse o sangue da recém-nascida seria corrompido e ela poderia adoecer gravemente.

Conta ele que um pouco antes de ocorrer o parto

[...] a parteira guarani tem que sentar e cuidar da mãe com o cachimbo (petyngua) e fazer o remédio das cinzas da fogueira para que a mãe tome antes de nascer a criança. Muitas vezes tem espírito mau dentro do mundo (tekoaxy) e por isso é importante que a criança nasça normal e a mãe fique bem. Então minha esposa ficou com dor de cabeça, com dor de barriga, isso é normal. Mas tem outra coisa que acompanha essa doença que é causada pelo espírito. Em primeiro lugar é preciso pegar a cinza e colocar no copo para mãe tomar para não ficar com dor no corpo todo. E o pai a mesma coisa. Nós temos que colocar uma panela cheia de cinza misturada na água, chamar todos os filhos e molhar as pernas de todos com isso e também todo o corpo. Isso é para evitar problemas, não ter dor e nem virar animal. Quando a criança nasce o pai tem que fazer balaio pequeno para menina e arco-eflecha pequeno para o menino. Assim evita acidente do nhe'ë, para que ele fique na aldeia e vá brincar com esse brinquedo e não acompanhar o pai se ele tiver que sair em outra aldeia. Se o espírito o acompanha ele pode se perder no caminho. Depois que o filho nasce o pai tem que ficar de resguardo durante trinta dias. Depois ele pode voltar as suas atividades normais. Neste período ele também não pode usar faca para que o umbigo do recém-nascido não inflame. Agulha também não, a mãe não pode costurar. Também não se pode cortar o umbigo com faca ou tesoura, nós cortamos com taquara. Mas o principal é fazer o balaio para a menina e o arco para o menino. Se não há resguardo as crianças sofrem muito, ficam com dor no corpo, choram. Depois de quinze dias da criança ter nascido a mãe deve lavar os pés na água quente de cinzas. Durante trinta dias a mãe não pode comer feijão, sal, doces, carne de porco. Ela só pode comer mandioca, batata doce, milho. Antigamente se proibia 
de comer tudo que é carne para que a mãe não tenha tonturas, porque quando matamos os animais eles não morrem na hora, eles ficam tonto antes de morrer. Hoje a gente come carne para ter força, mas isso também é decisão do branco. É importante que a mãe permaneça na aldeia para que ela não tenha recaída pois ela está espiritualmente fraca, sem conseguir falar alto, ainda está fraca a voz; e principalmente para que não cause doença na criança. Para que a mãe possa comer galinha depois de quinze dias a cunha-karaí tem que fazer oração e baixar a fumaça na galinha com o petyngua para tirar o veneno. A placenta também é importante, temos obrigação de enterrar na hora em que o nenê nasce. É importante enterrar a placenta para que a criança se lembre sempre da nossa cultura e da nossa tradição, porque senão ele vai esquecer. Porque a pessoa é natureza, ali ela se une com a natureza, com a terra. Na hora que enterramos a placenta vai a informação para os deuses, para o Pai Verdadeiro do Espírito que o nhe'ë chegou nessa terra. Também é preciso ter cuidado com a criança. É proibido que outras pessoas vejam a criança, por exemplo, se numa aldeia vem o bebedor e quer mexer nela ela pode ficar com dor de cabeça, ter pressão alta por causa da bebida alcoólica, porque ela é recém-nascida não está segura ainda, por isso pode pegar muita doença.

Com o processo histórico de contato interétnico, que intensificou a condição de imperfeição da terra onde os Mbyá habitam, algumas substâncias produzidas pelo 'mundo do branco' foram incorporadas no universo relacional dos Mbyá-Guarani. Tais substâncias, ainda que indigenizadas, compartilham a condição de imperfeição dessa terra e, por isso, são consideradas tekoaxy. Entre essas substâncias encontramos alguns alimentos (sal, azeite, açúcar, arroz) e também a bebida alcoólica. Ao serem consumidas elas contaminam a pessoa e as relações entre os parentes Mbyá.

\section{A Canha não Tem Parente}

Existem múltiplos fatores que contribuem para a construção do fenômeno do uso abusivo de bebidas alcoólicas entre os Mbyá-Guarani. O primeiro deles, reconhecido pelos Mbyá, diz respeito ao processo 
histórico de contato interétnico. Esse processo é o responsável pela construção de uma cultura do beber que articula um conjunto de práticas, significados e relações próprias à sociedade Mbyá a elementos provenientes da sociedade ocidental que foram incorporados e indigenizados por eles: alimentos, músicas, bebidas alcoólicas (Ferreira, 2002).

Práticas associadas ao consumo de álcool e incorporadas pelos Mbyá durante o contato são as "festas do branco" e os jogos de futebol. Estes são momentos de bebedeiras coletivas onde a maior parte dos corresidentes de uma determinada aldeia se envolvem. Nessas festas se consome cerveja, vinho e também aguardente, comumente chamada de canha. Os Mbyá afirmam que quando as pessoas bebem e dançam ao som da música do branco, sertaneja e forró universitário, gêneros musicais muito apreciados, o pensamento é direcionado ao sexo, enquanto os rituais realizados na opy mantêm o pensamentosentimento da pessoa ligado ao nhe'ë e a Nhanderu.

Na compreensão das lideranças espirituais Mbyá, o corpo da pessoa que se torna bebedora, ou melhor, o seu an, casa com o espirito da bebida alcoólica. Corpo e na aqui se confundem...

Porque como você está bebendo, quando você toma, não está pensando lá em cima, porque você ama, você gosta, você se apaixona por beber. Porque essa canha tem espírito! Por que a pessoa não quer parar? Porque o espírito do álcool está casado com seu corpo. Esse é o princípio! Quando você se sente tonto, ao tomar alcoólica se sente livre, sente uma coisa de natureza, vontade de fazer sexo, sente muita coisa. Esse espírito quando casou comigo, não queria parar nem um dia de beber, parece que não ia conseguir parar! (Cunha karaí, Salto do Jacuí).

Se casar entre os Mbyá constitui a prática por meio da qual se produz parentesco ao propiciar a concepção de crianças, o casamento do corpo da pessoa com a bebida alcoólica tende a negar os vínculos sociais estabelecidos entre os Mbyá. Isso porque, como diz um karaí Mbyá, "a canha não tem parente! Não tem pai, nem mãe, nem filhos, nem irmãos! A canha é sozinha". 
Justamente por ser sozinha que o espírito da canha promove a violência entre parentes. O bebedor ( $\underline{\mathrm{cau}})$ que não tem limites e nem controle para beber e que se torna violento afeta os seus parentes mais próximos. De acordo com os Mbyá, o cau não tem condições de cuidar de sua família, pois bebe até cair ou até acabar a bebida, além disso ele gera sofrimento para os seus parentes. Um bebedor certa vez me contou que sempre quando bebia ele encontrava uma pessoa muito bonita com quem se divertia, ao mesmo tempo, essas lindas pessoas faziam com que ele olhasse para a sua esposa como se fosse o próprio demônio. Por isso, a agredia fisicamente, a ponto de o Ministério Público Federal ter que intervir para impedir que a violência doméstica se perpetuasse.

Dentre os problemas causados pelo bebedor que casa com a canha estão as desavenças conjugais. Geralmente quando embriagados, o motivo dos conflitos e das separações entre casais o ciúme, a desconfiança e a traição. Por isso os karaí transmitiam esses conselhos aos casais:

Todos os que casam tem que procurar viver bem. Essa separação existe em todas as partes, não é só aqui. Nisso tem ainda quando o pai da sua filha bebe e fala bobagem. Ai a mulher fica sofrendo, porque ela não bebe. Então isso acontece em alguns casais, isso é que causa dor. Então qualquer coisinha e chega o momento de entregar o corpo para outro espírito, o espírito da canha. Se casal bebe junto aí não tem controle (Karaí, Salto do Jacuí).

A grande preocupação dos sábios Mbyá no que diz respeito ao uso abusivo de bebidas alcoólicas se refere a condição de vulnerabilidade das crianças quando a maioria dos adultos se encontra embriagada. Nessas situações os pais, geralmente, esquecem a forma ensinada pelos deuses para cuidarem de seus filhos. Os karaí afirmam que hoje os pais não sabem mais os motivos pelos quais os deuses enviaram os nhe'ë de seus filhos para essa terra. Isso se deve ao fato de, entre outras coisas, não observarem as restrições recomendadas para o período de gravidez e o puerpério e por manter sua energia vital comprometida com a canha. Dentre as restrições que os pais devem observar durante a gestação e o resguardo pós-parto está a de não beber para evitar que a saúde da criança não seja prejudicada. 
Por que hoje em dia, o pai e a mãe não sabem respeitar a criança, o seu filho? Quando a mulher está grávida não pode andar com outro homem ou com outra mulher. O pai e a mãe têm que valorizar as crianças. Se a mãe está grávida o marido tem que respeitar a mulher, não pode fazer sexo com outra. O espírito chora se vê o pai fazendo sexo com outra mulher. Então para que o espírito venha com alegria, para nascer saudável, vir bem de saúde, não pode beber canha! O pai e a mãe têm que saber que está vindo as crianças dos deuses. Porque antes de incorporar nas crianças, Deus manda uma prova para o pai e para mãe. Se acontece de não passar na prova, na criança vai chegar outro espírito que não é nhe'ë, porque o pai não sabe esperar a incorporação da criança. As vezes o nhe'ë vai embora por causa da briga do pai e da mãe. Isso já aconteceu aqui. Não se pode assustar as crianças, porque senão o nhe'ë pode voltar para casa. Quando nós temos crianças, nós temos que cuidar bem, não podemos brigar. A criança tem que ser bem tratada. Por que quê o Sol está vindo, brilhando neste mundo ainda? Porque ainda existem as crianças, porque elas estão nascendo ainda. Quando tem criança pequena os pais não podem beber muito! A canha é que traz doença para as crianças. Porque quando a mãe e o pai bebem, se a criança está na barriga, a criança fica sofrendo pelo calor da canha (cunha-karaí, Canta Galo).

Outro problema causado pelo consumo de álcool, já que a canha não tem parente, é facilitar tanto as relações sexuais incestuosas entre consanguíneos, quanto com pessoas não-mbyá - que devem ser evitadas, segundo orientação dada pelos mais velhos aos jovens. Um karaí explica sobre o que acontece com aquele que bebe e que mantém relações sexuais inapropriadas. Os filhos gerados por estas relações, idealmente, não poderiam ser nem batizados e nem tratados pelos karaí.

Porque se não é tomadora de cachaça, a índia também não vai gostar de branco. Porém, uma vez que tomou, qualquer branco aceita fazer sexo com ela para aproveitar! Porque antes, quando não existia tomadora de cachaça, a quenga não existia entre nós! Daí traz a doença para dentro da aldeia: pega homem, pega esposo. Por culpa disso agora o médico do índio não pode resolver todo enfermidade. O médico do índio é karaí! Para levar no 
karaí, para tratar junto com karaí, a família tem que pensar primeiro! Família de quem é? Quem é o pai? Quem é a mãe? Quem é que começou essa criança? Porque agora não se sabe quem é o pai, quem começou a criança! Isso causa muito problema! Muito trabalho temos que fazer. Daí quando está doente karaí não sabe ou karaí não pode trabalhar, porque pai não tem! (Karaí, Torres).

Quando o corpo da pessoa está casado com o espírito da bebida alcoólica, ela bebe demais e perde o "sentido", ultrapassando os limites culturalmente instituídos. Ao não observar as orientações repassadas pelas divindades sobre o correto modo de viver nessa terra, a pessoa Mbyá age contra o seu nhe'ë que, ao não possuir alternativa, afasta-se dela deixando-a sem proteção. Sem contar com a proteção do nhe'ë, ela se torna vulnerável aos vários perigos a ameaçam, dentre eles aos atasques dos mboguá (espirito dos mortos) e dos anhã (seres perversos), que passam a exercer uma influência nefasta sobre a pessoa levando o bebedor a brigar com seus parentes, a adoecer ou até mesmo a morrer. Uma liderança Mbyá fala sobre a preocupação dos karaí com os parentes que deixaram 'seu corpo como terra':

Saudações meus parentes. Eu também não sei falar muita coisa. Eu também vou falar um pouco sobre a bebida alcoólica. Eu também era feio (bebedor). Nossos parentes estão diminuindo, já perdemos muito. Muitos dos nossos parentes já ficaram com o corpo como terra só por causa da bebida alcoólica. Eu sei também porque eu era bebedor. Os mais velhos e mais velhas sofrem muito quando o filho ou a filha é bebedor. Então quando os filhos falam assim: o problema é meu se estou bebendo, sou eu que bebo! Os pais sofrem, por que se ele morrer, isso é dor para toda a família. Quando o meu parente morre, vem o sofrimento para todos. Os karaí estão orientando para não chegarmos no ponto de cairmos no buraco e morrermos. Então, por isso que os mais velhos se preocupam! (Xondaro marãgatu, Campo Molhado). 


\section{Considerações Finais}

Talvez a substancialidade como linguagem organizadora do parentesco dos povos ameríndios não tenha sido utilizada para pensar o parentesco Guarani devido ao fato dos estudos etnológicos clássicos sobre os guarani (Cadógan, 1950; Meliá, 1988; 1989; Clastres, 1978; Schaden, 1954; Nimuendajú, 1987) enfatizarem a preeminência da religião sobre as outras dimensões da vida social - política, econômica, artística - destacando, por um lado, o conceito de alma nativo como chave para a compreensão desse sistema; e, por outro lado, o tema mitológico da busca da terra sem mal e de como tal busca refletiria a negação da própria sociedade (Clastres, 1978). As teorias de corporalidade ainda não foram consideradas como princípios centrais da estruturação do modo de ser Mbyá, sendo apenas algumas notas endereçadas por esses estudos ao lugar que o corpo ocupa como idioma simbólico focal nessa sociedade indígena, mas nunca como um aspecto tão importante, quanto o metafísico. Nesse sentido, as relações de substância como dispositivo de produção de pessoas e de identidades sociais permaneceram invisíveis aos estudos sobre a organização social e as relações de parentesco Guarani.

No entanto, não apenas as práticas de resguardo descritas acima apontam para o fato do idioma da substancialidade constituir o operador simbólico no processo de produção da pessoa aparentada, mas a própria teoria nativa que afirma que o corpo da pessoa que bebe casa com o espírito da bebida alcoólica, demonstram o quanto esse idioma informa as relações entre parentes Mbyá-Guarani. O uso abusivo de álcool ameaça os vínculos sociais, porque a canha é uma substância que não possui parentes. É justamente por ser sozinha que ela não só é incapaz de produzir parentesco como tampouco pode fortalecer os vínculos já existentes. Por outro lado, essa é uma substância proveniente do 'mundo do branco' que se instala no coração do sistema de partilha Mbyá, ali mesmo onde são construídas as pessoas aparentadas. Nesse sentido, a violência familiar é o efeito criado por um espírito estrangeiro que não possuí parentes, mas quer relacionar-se.

Se o casamento do corpo com o espírito da bebida alcoólica faz com que o nhe'ë se afaste é porque para manter-se vinculado a pessoa 
ele precisa de uma condição corporal adequada. Para cuidar do seu corpo, o Mbyá precisa observar o fluxo das substâncias partilhadas não apenas entre parentes, mas também com os demais seres que habitam o seu cosmos. Dessa ligação entre o nhe'ë e o corpo depende o bemestar e a boa saúde das pessoas e dos coletivos Mbyá. O espírito divino se afasta quando os princípios cosmológicos que regulam o fluxo de substâncias corporais não são respeitados. A relação entre a dimensão espiritual e o corpo das pessoas é simbolicamente mediada pelo idioma da substancialidade. Portanto, como um conjunto de afetos, afecções e capacidades, o corpo Mbyá adequado para o assentamento do nhe'ë é aquele moldado justamente pelas relações de substância que tem lugar nos espaços de convívio entre parentes. À pessoa cabe o papel de zelar pela pureza dos fluídos corporais, não os contaminando por meio do contato com os seres e substâncias tekoaxy, para que o nhe'ë encontre as condições necessárias para continuar ligado a ela, protegendo-a.

Entre os Mbyá, o idioma da substancialidade e o idioma do cuidado, diferente das sociedades do Baixo Urubamba (Gow, 1991), fazem parte de um mesmo processo de produção da pessoa aparentada. O cuidado com o fluxo de substâncias corporais é fundamental para que a criança se desenvolva com saúde e para que o adulto a mantenha, na medida que é desse cuidado depende a sua conexão com o nhe'ë. Por outro lado, diferente dos Apinayé descrito por Da Matta (1979), entre os Mbyá a lógica da substância não apenas informa e orienta a relação entre parentes tanto no âmbito doméstico quanto nos contextos comunitários das aldeias, mas também se estende para além dos domínios do parentesco.

Ela abarca e informa as relações sociocosmológicas estabelecidas entre os Mbyá e os outros seres - humanos ou não - que habitam o cosmos. Dentre eles, estão o próprio juruá e as coisas provenientes do seu mundo que, apesar de apropriadas e indigenizadas, não deixam de ser tekoaxy e de contaminar o corpo Mbyá quando contatos impróprios são estabelecidos. Essa lógica está posta tanto para a restrição no que tange a relação sexual com os não-mbyá, já que o contato com o sangue do juruá contaminaria o sangue mbyá impedindo que o nhe'ë se mantenha vinculado ao corpo da pessoa; quanto para o consumo 
do álcool e a relação estabelecida com o espírito dessa substância que compromete os vínculos de parentesco entre Mbyá.

É por meio do idioma de substancialidade que os vínculos entre corpo e espírito são estabelecidos e que a pessoa Mbyá, em relação com as outras, é construída. Assim, colocar a ênfase da análise sobre a “[...] noção de pessoa e na corporalidade como idioma focal, evitaria cortes etnocêntricos em domínios ou instâncias sociais como 'parentesco', 'economia', 'religião'" (Segger, Da Matta, Viveiros de Castro, 1987, p. 26). Portanto, a compreensão das teorias da corporalidade e do idioma de substancialidade que informa as relações entre parentes e desses com os Outros que habitam o mundo constitui uma chave interpretativa importante para a compreensão dos fenômenos vivenciados pelos Mbyá-Guarani contemporâneos, estando ainda por ser desenvolvida.

\section{Agradecimento:}

Agradecimentos ao CNPq pela concessão da bolsa de Pós-Doutorado Júnior que viabilizou a elaboração desse artigo.

\section{Notas}

1 Para um aprofundamento da reflexão acerca dos processos de alcoolização experienciados por sociedades indígenas no Brasil ver Fernandes (2011); Langdon (1999); Langdon (2013); Oliveira (2004); Souza (2013).

2 O presente artigo faz parte do projeto de PDJ/CNPq "Políticas de saúde indígena e novos regimes de subjetivação" que tem como objetivo analisar os efeitos das políticas de saúde indígena sobre as relações sociais, as práticas e os processos de produção de corpos e de pessoas indígenas e a instauração de novos regimes de subjetivação.

3 Outro estudo que contribuiu para a compreensão do processo de produção da pessoa aparentada Mbyá-Guarani foi o realizado por Testa (2014).

\section{Referências}

BARTOLOMÉ, Miguel Alberto. Chamanismo y Religion entre los AvaKatu-Ete. Assunción: Centro de Estudios Antropológicos, 1991.

CADÓGAN, León. La encarnación e la concepción: la muerte y la resurrección en la poesía sagrada 'esotérica' de los Jeguaká-va Tenondé Porã-güé (Mbyá-Guarani) del Guairá, Paraguay. Revista do Museu Paulista, São Paulo, v. IV, n. s. 1950. 
CLASTRES, Helenè. A Terra sem Mal. São Paulo: Brasiliense, 1978.

DA MATTA, Roberto. The Apinayé relationship system: terminology and ideology. In: MAYBURY-LEWIN, David (Org.). Dialectical Societies, the Gê and Bororo of Central Brazil. Cambridge: Harvard university Press, 1979. p. 83-127.

FERNANDEZ, João Azevedo. Selvagens bebedeiras: álcool, embriaguez e contatos culturais no Brasil Colonial (séculos XVI-XVII). São Paulo: Alameda, 2011.

FERREIRA, Luciane O. Mba'e Achÿ: a Concepção Cosmológica da Doença entre os Mbyá-Guarani num Contexto de Relações Interétnicas. 2001. Dissertação (Mestrado em Antropologia Social) - Universidade Federal do Rio Grande do Sul, Porto Alegre, 2001.

FERREIRA, Luciane O. O Impacto do Uso Abusivo de Bebidas Alcoólicas sobre a Pessoa Mbyá-Guarani - RS. Revista Tellus, Campo Grande: UCDB, ano 2, n. 2, p. 39-64, 2002.

FERREIRA, Luciane O. As "Boas Palavras" dos Xondaro Marãgatu como Alternativa para a Redução do Consumo de Bebidas Alcoólicas entre os Mbyá-Guarani - RS. Revista Tellus, Campo Grande: UCDB, ano 4, n. 7, p. 121-135, 2004.

FERREIRA, Luciane O. “O 'Fazer Antropológico' em Ações Voltadas para a Redução do Uso Abusivo de Bebidas Alcoólicas entre os Mbyá-Guarani no RS". In: LANGDON, Esther Jean; GARNELO, Luiza (Org.). Saúde dos Povos Indígenas: reflexões sobre Antropologia Participativa. São Paulo: Contracapa, 2004. p. 89-110.

FERREIRA, Luciane O. A emergência das boas palavras na $1^{a}$ Reunião dos Karaí sobre o uso abusivo de bebidas alcoólicas e alcoolismo no RS. In: SILVA, Gilberto Ferreira da; PENNA, Rejane; CARNEIRO, Luiz Carlos da. RS Índio - Cartografias sobre a Produção do Conhecimento. Porto Alegre: EDIPUCRS, 2009. p. 154-167.

FERREIRA, Luciane O. Saúde e relações de gênero: uma reflexão sobre os desafios para a implantação de políticas públicas de atenção à saúde da mulher indígena. Ciência e Saúde Coletiva, Rio de Janeiro: Fiocruz, v. 18, n. 4, 2013. p. 1.151-1.159.

GOW, Peter. Of Mixed Blood: Kinship and History in Peruvian Amazonia. New York: Clarendon Press-Oxford, 1991.

LANGDON, Esther Jean. O Que Beber, Como Beber e Quando Beber: o contexto sociocultural no alcoolismo entre as populações Indígenas. In: LANGDON, Esther Jean. Saúde, Saberes e Ética: três conferências sobre antropologia da saúde. Antropologia em Primeira Mão. Florianópolis: PPGAS/UFSC, 1999. 
LANGDON, Esther Jean. O abuso de álcool entre os povos indígenas no Brasil: uma avaliação comparativa. In: SOUZA, Maximiliano Loiola Ponte (Org.). Processos de alcoolização indígena no Brasil: perspectivas plurais. Rio de Janeiro: Editora Fiocruz, 2013.

LARRICQ, Marcelo. Ipytuma, construcción de la persona entre los Mbya-Guaraní. Misiones: Editorial Universitaria, Universidad Nacional de Misiones, 1993.

LITAIFF, Aldo. As Divinas Palavras: Identidade Étnica dos GuaraniMbyá. Florianópolis: EdUFSC, 1996.

MELIA, Bartomeu. Los Guarani-Chiriguano: Ñande Rekó, nuestro modo de ser. La Paz: Cipca, 1988.

MELIA, Bartomeu. La Terra-sin-Mal de los Guarani: Economia y Profecia, América Indígena: México, v. XLIX, n. 3, 1989. p. 491-507.

MENENDEZ, Eduardo. Modelos de atenção dos padecimentos: exclusões ideológicas e articulações práticas. In: MENENDEZ, Eduardo. Sujeitos, saberes e estruturas: uma introdução ao enfoque relacional no estudo da saúde coletiva. São Paulo: Hucitec, 2009.

NIMUENDAJU, Curt. As Lendas de Criação e Destruição do Mundo: como Fundamentos da Religião dos Apapocúva-Guarani. São Paulo: Hucitec-Edusp, 1987.

PISSOLATO, Elizabeth. A duração da pessoa - mobilidade, parentesco e xamanismo Mbyá (guarani). São Paulo: ISA/UNESP/NUTI, 2007.

OLIVEIRA, Marlene. A intervenção como um processo em construção: notas para a redução do uso de bebidas alcoólicas e alcoolismo entre os kaingang. In: LANGDON, Esther Jean, GARNELO, Luiza (Org.). Saúde dos Povos Indígenas: reflexões sobre Antropologia Participativa. Rio de Janeiro: Contracapa, 2004.

PEREIRA, Levy Marques. Parentesco e organização social kaiowá. 1999. 245p. Dissertação (Mestrado em Antropologia Social) - Universidade Estadual de Campinas, Campinas, 1999.

POTY, Vherá. Os Guarani Mbyá. Porto Alegre: Wences Design Criativo, 2015.

SAEZ, Óscar Calávia. La persistência guarani - Introducción. Revista de Índias, Espanha, v. 230, n. 64, 1984. p. 97-116.

SEEGER, Anthony; DA MATTA, Roberto; VIVEIROS DE CASTRO, Eduardo. A construção da Pessoa nas Sociedades Indígenas Brasileiras. In: OLIVEIRA FILHO, João Pacheco (Org.). Sociedades Indígenas e Indigenismo no Brasil. Rio de Janeiro: Marco Zero/UFRJ, 1987. p. 11-29. 
SEEGER, Anthony. Corporação e Corporalidade: Ideologias de concepção e descendência. In: SEEGER, Anthony. Os índios e Nós: estudo sobre sociedades tribais brasileiras. Rio de Janeiro: Ed. Campus Ltda., 1980. p. 127-132.

SOARES, André Luís. Guarani: Organização Social e Arqueologia. Porto Alegre: EDIPUCRS, 1997.

SCHADEN, Egon. Aspectos Fundamentais da Cultura Guarani. SP, EPU-EDUSP, 1954.

SOUZA, Maximiliano Loiola Ponte de (Org.). Processos de alcoolização indígena no Brasil: perspectivas plurais. Rio de Janeiro: Editora Fiocruz, 2013.

TESTA, Adriana Queiroz. Caminhos de sabers Guarani Mbyá: modos de criar, crescer e comunicar. 2014. Tese (Doutorado em Antropologia Social) - Universidade de São Paulo, São Paulo, 2014.

VIVEIROS DE CASTRO, Eduardo. Araweté os Deuses Canibais. Rio de Janeiro: Jorge Zahar, 1986.

VIVEIROS DE CASTRO, Eduardo. A fabricação do Corpo na Sociedade Xinguana. In: OLIVEIRA FILHO, João Pacheco (Org.). Sociedades

Indígenas e Indigenismo no Brasil. Rio de Janeiro: Marco Zero/UFRJ, 1987. p. 31-41.

VIVEIROS DE CASTRO, Eduardo. Os Pronomes Cosmológicos e o Perspectivismo Ameríndio. Mana, Rio de Janeiro: PPGAS-Museu Nacional/UFRJ, v. 2, n. 2, p. 115-144, 1996.

VIVEIROS DE CASTRO, Eduardo. Atualização e contra-efetuação do virtual: o processo de parentesco. In: VIVEIROS DE CASTRO, Eduardo. A inconstância da alma selvagem e outros ensaios de antropologia. São Paulo: Cosac \& Naify, 2002. p. 401-455.

Recebido em 25/04/2017

Aceito em 02/06/2017 